\title{
Search for Drosophila caspases bears fruit: STRICA enters the fray
}

\author{
C Adrain ${ }^{1}$ and SJ Martin ${ }^{\star, 1}$ \\ ${ }^{1}$ Molecular Cell Biology Laboratory, Dept. of Genetics, The Smurfit Institute, \\ Trinity College, Dublin 2, Ireland \\ * Corresponding author: SJ Martin, Molecular Cell Biology Laboratory, Dept. of \\ Genetics, The Smurfit Institute, Trinity College, Dublin 2, Ireland. \\ Tel: 353-1-608-1289; Fax: 353-1-679 8558; E-mail: martinsj@tcd.ie
}

Caspases occupy a central position at the heart of the programmed cell death (PCD) machinery - from nematodes to man. In addition to their role in PCD, caspases also play an important role in the innate immune response through the processing of pro-inflammatory cytokines. ${ }^{1,2}$ Much of what we know about caspase structure, function and regulation has been gleaned from studies on human and murine caspases. To date, 14 human caspases have been cloned, of which, approximately seven participate in apoptosis. Mammalian caspases implicated in PCD can be broadly subdivided into initiator (upstream) and executioner (downstream) proteases based on the length of their N-terminal prodomains. ${ }^{3}$ Initiator caspases appear to play a pivotal role at the apex of proapoptotic signalling cascades, serving to initiate the proteolytic avalanche that culminates in activation of executioner caspases and demolition of the cell. ${ }^{3}$

Although several murine caspases have been inactivated through gene targeting, the impact of these knockouts on developmental PCD has been surprisingly modest. ${ }^{4,5}$ Thus, much remains to be understood concerning the role of caspases in development, as well as tissue homeostasis in the adult. ${ }^{4,5}$ Drosophila melanogaster has long since proved its worth as a model organism for the dissection of complex cellular processes such as pattern formation and dorsal-ventral polarity specification during early development. Thus, although studies on PCD regulation in the fly have largely confirmed observations made in mammalian systems thus far (with the notable exception of the discovery of the rpr, hid and grim loci), Drosophila clearly has much more to offer in terms of our understanding of the role(s) that caspases play within complex biological settings. ${ }^{6,7}$

To date, five Drosophila caspases have been described, with members of both the long and short prodomain classes represented within this repertoire ${ }^{2}$ (Figure 1). In this issue of Cell Death and Differentiation, a new addition to the fly caspase armory, STRICA (serine-threonine rich caspase) is reported by Kumar and colleagues. ${ }^{8}$ STRICA appears to be a long prodomain caspase, but with an interesting twist. The highly serine and threonine rich STRICA prodomain bears no similarity to any previously described caspase prodomain, suggesting that STRICA activation may be regulated in a novel way. ${ }^{8}$

\section{Drosophila executioner caspases}

Of the caspases thus far identified in Drosophila, four of these: DCP-1, drICE, DECAY and the yet uncharacterized caspase, DAMM, fall into the category of executioners..$^{2,9-11}$ By analogy with mammalian caspases, this characterization is based upon several criteria, including a short or absent prodomain and the ability to process certain synthetic peptide substrates. $^{2,3}$ DCP-1, drICE and DECAY all share significant sequence similarity with the well characterized human executioner caspase, caspase-3, and screening of combinatorial peptide libraries suggest that these caspases also exhibit a caspase-3-like preference for DXXD motifs. ${ }^{2,9-12}$ Moreover, several of these small prodomain enzymes can cleave Drosophila proteins that are conserved relatives of human caspase substrates. ${ }^{2}$ For example, active drICE can cleave PARP, Drosophila lamin (DmO), Drosophila ICAD (dICAD), and the prototypical caspase inhibitor, baculovirus p35. $2,13-15$

Studies on human caspases suggest that the short prodomain caspases are dependent upon initiator caspases for their activation. ${ }^{3}$ For example, initiator caspase- 9 proteolytically processes executioner caspases -3 and $-7 .^{16}$ While caspase cascades have yet to be extensively analyzed in Drosophila, preliminary evidence suggests that at least one putative initiator enzyme, DRONC, can process and activate drICE. ${ }^{17}$ This suggests that initiator/executioner hierarchies similar to those elucidated for mammalian caspases, also pertain in the fly.

\section{DRONC and DARK: the fly apoptosome?}

In common with the upstream components of many signalling pathways, the activation of initiator caspases is tightly regulated. Protein-protein interaction motifs contained within the N-terminal regions of certain human and fly caspases appear to play a critical role in regulating the activation of these caspases. ${ }^{18}$ hCaspase- 9 and DRONC both possess a six $\alpha$-helical bundle within their prodomains termed the CARD motif (caspase recruitment domain). ${ }^{19-21}$ The Caspase-9 CARD facilitates interaction of the latter with a similar CARD motif present within the $\mathrm{N}$-terminus of the caspase-activating molecule, Apaf-1.22

In a similar vein, DRONC (and somewhat surprisingly DREDD) can interact with the Drosophila Apaf-1 orthologue, DARK (dAPAF-1/HAC-1). ${ }^{23-25}$ Moreover, extracts derived from Drosophila mutants devoid of DARK expression exhibit reduced DRONC activation, suggesting that these molecules constitute the functional equivalents of human Apaf-1/ caspase-9. ${ }^{23,24}$ This suggests that fly and human initiator caspases are activated by similar mechanisms. ${ }^{23-26}$ 


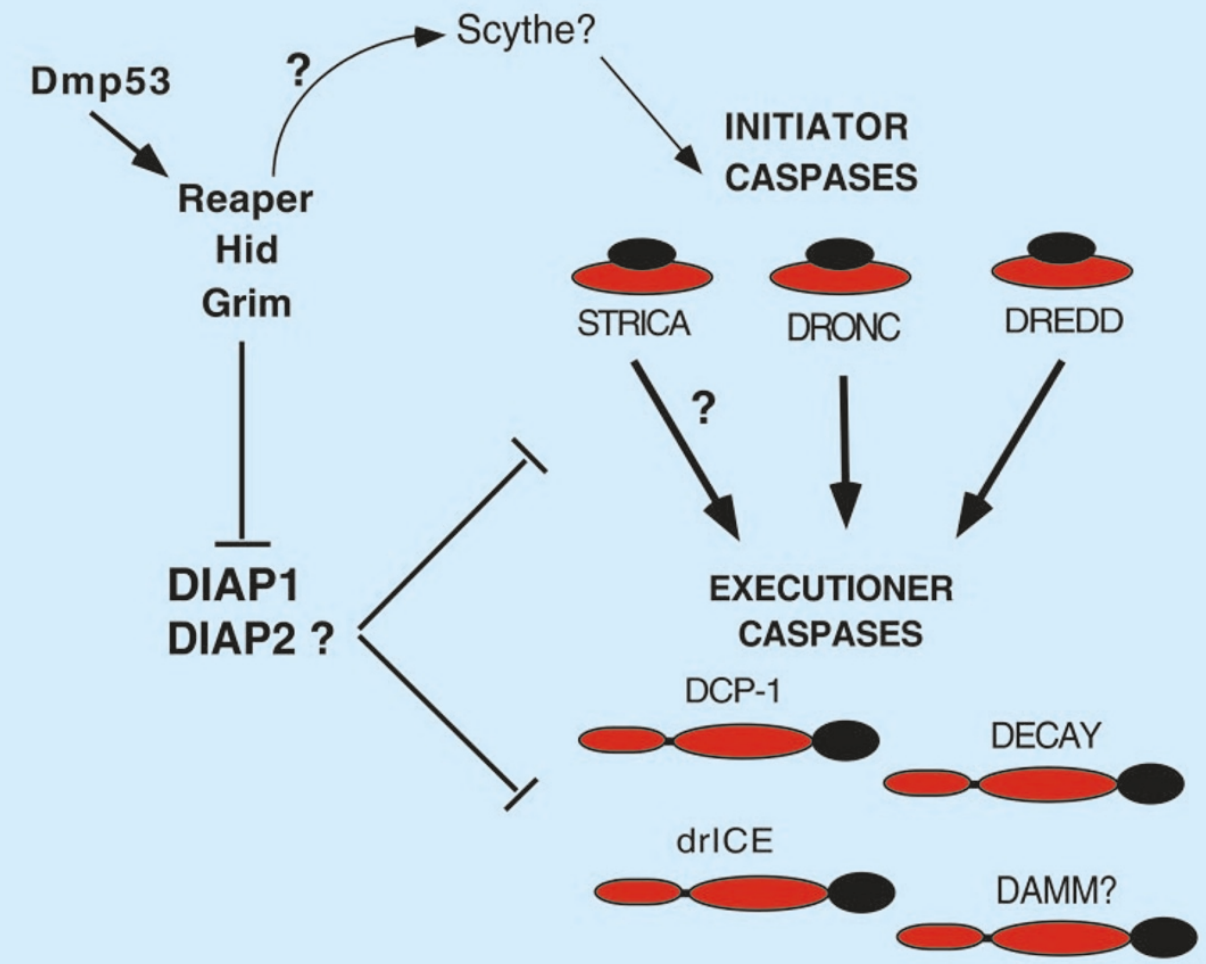

Figure 1 Hypothetical view of caspase regulation in Drosophila. Note that the division of caspases into initiators and executioners is based largely on their prodomain length

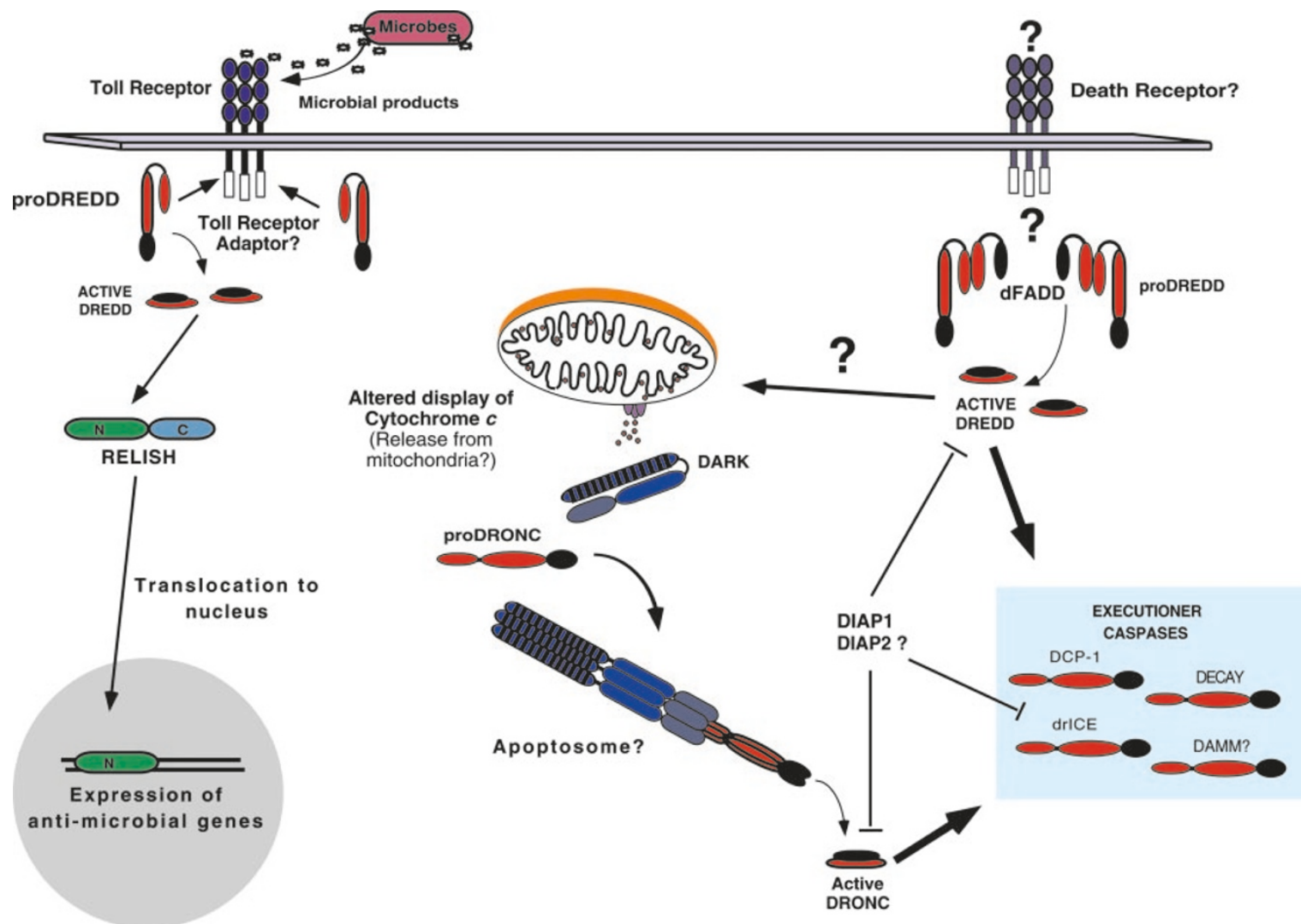

Figure 2 Hypothetical network of Drosophila signalling pathways that result in initiator caspase activation 
Assembly of the mammalian Apaf-1/Caspase-9-activating complex, called the apoptosome, requires cytosolic cytochrome $c$ and dATP as co-factors. ${ }^{22,27}$ Cytochrome $c$ and dATP have also been found to trigger DARKdependent activation of executioner caspases in extracts of Drosophila embryos, suggesting that DARK and Apaf-1 may be regulated in a similar way. ${ }^{24}$ Indeed, DARK possesses the C-terminal WDR (WD-40 repeat region) known to be required for binding of cytochrome $c$ to Apaf-1 and DARK can bind cytochrome $c$ in vitro. ${ }^{23-25}$ However, although a novel cytochrome $c$ epitope is exposed during Drosophila PCD, it remains unclear whether this respiratory chain component exits the mitochondrial intermembrane space during fly PCD, as has been observed in mammals. ${ }^{28}$

Evidence suggests a role for DRONC as an effector of steroid induced apoptosis in the fly, as DRONC message levels increase massively in the salivary glands and midgut of third instar larvae in response to fly steroid, ecdysone. ${ }^{21}$ Interestingly, DARK levels are also high during the onset of histolysis within this period, in the third instar and early pupation stages. ${ }^{23}$ It is currently unclear what role DARK plays within the pathway(s) downstream of death agonists rpr, hid and grim. ${ }^{2,23-25}$ However, a dominant negative mutant of DRONC has been reported to suppress death provoked by expression of Reaper and Hid in the Drosophila eye. ${ }^{17}$

\section{A death domain adaptor for DREDD, but death receptors remain elusive}

In addition to the CARD motif, a related motif similar to the mammalian death effector domain (DED) is also utilized in components of the fly PCD machinery. 2,6,29 Two DEDs are contained within the prodomain of the initiator caspase, hCaspase-8, that act as the molecular glue to recruit the latter to membrane death receptors of the TNF receptor superfamily. ${ }^{30}$ The Drosophila caspase-8 counterpart, DREDD, also possesses two copies of a DED-like motif within its prodomain. ${ }^{2,31}$ In mammals, the adaptor molecule FADD (which also possesses a DED motif) bridges caspase-8 to the cytoplasmic tails of membrane death receptors. ${ }^{32}$

The recent identification of a DREDD-interacting FADD homologue (dFADD) in the fly demonstrates conservation of the DED-based interaction system as a means of regulating Drosophila caspase activation. ${ }^{29}$ Consistent with its putative role as a FADD-like caspase adaptor protein, dFADD interacts with the prodomain of DREDD and enhances its processing and pro-apoptotic activity. ${ }^{29}$ Like FADD, dFADD also possesses yet another proteinprotein interaction motif that repeatedly crops up among proteins involved in mammalian PCD pathways - the death domain motif. However, while the death domain of dFADD is highly homologous to that of its human counterpart and to those found within human death receptors, death receptors have yet to be identified in the fly. ${ }^{29}$

\section{DREDD and Relish take their Toll on microbial infections}

In addition to a role for DREDD in pro-apoptotic signalling pathways, recent studies suggest that DREDD also participates in the innate immune response to microbial components routed through the Toll receptor pathway. ${ }^{33,34}$ DREDD plays a required role in the proteolytic processing and thus activation - of the NF- $\kappa$ B-related transcription factor, Relish, in response to gram-negative bacterial infection. ${ }^{33,34}$ Nuclear translocation of the $\mathrm{N}$-terminal cleavage product of Relish facilitates the expression of several anti-bacterial genes. ${ }^{33,34}$ While proteasome-independent, endoproteolytic $\mathrm{NF}-\kappa \mathrm{B}$ activation has yet to be reported in mammals, caspase- 8 has been reported to potentiate NF- $\kappa$ B activation in certain situations. ${ }^{35}$ In addition, mammalian Caspase-1 (ICE) is well known to play an essential role in the endoproteolytic maturation of IL-1 $\beta$, the mature form of which can stimulate NF- $\kappa \mathrm{B}$ activation upon release from the cell. ${ }^{36}$ Thus, a role for caspases in activating proteins involved in pathogen responses has been preserved from flies to men.

\section{STRICA: A novel long prodomain caspase}

As we have discussed, the CARD and DED motifs of the long prodomain caspases play important roles in regulating caspase activation. In this context, the discovery of STRICA may represent a third species of initiator caspase in Drosophila. $^{8}$ Using a database interrogation approach, Doumanis and colleagues ${ }^{2,8}$ identified STRICA as a caspase that is most homologous to DREDD and caspase-8. In common with DREDD and DRONC, STRICA possesses a long prodomain which suggests that this caspase may play a role at the apex of a signalling pathway. ${ }^{2,8}$

In common with many caspases, overexpression of STRICA provokes apoptosis, providing tentative evidence that STRICA may participate in PCD in the fly. ${ }^{8,11,21}$ STRICA is expressed widely during development, including the midgut and salivary glands of third instar larvae that become deleted during morphogenesis from larva to pupa, again suggesting a role for STRICA in the regulation of Drosophila apoptosis. ${ }^{2,8}$ However, given the precedent that Drosophila and mammalian caspases may also regulate pro-inflammatory processes, a non-PCD role for STRICA is also possible. . $^{33,34}$

What distinguishes STRICA from other long prodomain caspases in Drosophila is the lack of similarity between the STRICA prodomain and the CARD or DED-like motifs found in DRONC or DREDD. Indeed, the abundance of ser/ thr residues within STRICA, which constitute some $27 \%$ of the entire molecule, is a feature lacking in other caspases and other cell-death regulatory molecules-with the possible exception of Xenopus cytochrome $c$ releasepromoting factor, SCYTHE. ${ }^{7,37}$

Based on the length of the STRICA prodomain it is tempting to speculate that this molecule functions as an initiator caspase. An important question in this regard relates to the regulatory role of the STRICA $\mathrm{N}$-terminus. Unlike several other caspase prodomains, the STRICA Nterminus does not appear to self-associate. ${ }^{8}$ However, this does not exclude the possibility that the STRICA prodomain may function as an interaction motif for recruitment of other, putative adaptor, proteins. Given the abundance of serine/ threonine residues, one obvious possibility is that STRICA activation or activity may be modulated by phosphorylation 
at one or more serine or threonine residues within the prodomain.

In common with other fly caspases, including DRONC, DREDD, DCP-1 and DRICE, apoptosis induced by STRICA can be attenuated by co-expression of the Drosophila IAP, DIAP-1. 2,9,21,31 However, what sets STRICA apart from other fly caspases is its ability to interact with DIAP-2, at least when these molecules are over-expressed within the same cell. ${ }^{8}$ While there is ample evidence for a role for DIAP-1 as a caspase inhibitor, the role of DIAP-2 is somewhat enigmatic since deficiencies in the DIAP-2 locus have no effect on rpr or hid-induced death in the Drosophila eye model of cell death. ${ }^{7,38}$ Determining whether STRICA is a physiological target of DIAP-2 may therefore prove useful in dissecting the role of this IAP molecule.

Another puzzle posed by the current study is that while STRICA overexpression induces apoptosis, bacterially expressed STRICA does not appear to exhibit enzymatic activity when tested on classical tetrapeptide substrates that are recognized by a variety of caspases. ${ }^{8}$ However, given that at least one fly caspase, DRONC, can recognize glutamate residues as well as the classical aspartate residue in the $\mathrm{P} 1$ substrate position, a wider search may well yield the preferred substrate of STRICA. ${ }^{8,17}$

Clearly, many questions concerning the role of STRICA in the fly remain unanswered. The current study does not shed any light on the mechanism of STRICA activation, or the context within which this caspase may operate. However, given the striking conservation between regulation of PCD in the fly and mammals, further dissection of the role of this caspase within the context of STRICA-null flies is keenly awaited.

\section{Acknowledgements}

We are indebted to The Wellcome Trust, The Health Research Board of Ireland, Enterprise Ireland and The European Community for support of ongoing research in our laboratory.

\section{References}

1. SleeEA, Adrain Cand Martin SJ (1999) Serial killers: ordering caspase activation events in apoptosis. Cell Death Differ. 6: 1067-1074

2. Kumar S, Doumanis J (2000) The fly caspases. Cell Death Differ. 7: 1039-1044

3. Cohen GM (1997) Caspases: the executioners of apoptosis. Biochem J. 326:1 16

4. Zheng TS, Hunot S, Kuida K and Flavell RA (1999) Caspase knockouts: matters of life and death. Cell Death Differ. 6: 1043-1053

5. Zheng TS and Flavell RA (2000) Divinations and surprises: genetic analysis of caspase function in mice. Exp. Cell. Res. 256: 67-73

6. Vernooy SY, Copeland J, Ghaboosi N, Griffin EE, Yoo SJ and Hay BA (2000) Cell death regulation in Drosophila: conservation of mechanism and unique insights. J. Cell. Biol. 150: F69-F76

7. Hay BA (2000) Understanding IAP function and regulation: a view from Drosophila. Cell Death Differ. 7: 1045-1056

8. Doumanis J, Quinn L, Richardson H and Kumar S (2001) STRICA, a novel Drosophila caspase with an unusual serine/threonine-rich prodomain, interacts with DIAP1 and DIAP2. Cell Death Differ. 8: 387-394

9. Song Z, McCall K and Steller H (1997) DCP-1, a Drosophila cell death protease essential for development. Science 275: 536-540
10. Fraser AG, McCarthy NJ and Evan GI (1997) drICE is an essential caspase required for apoptotic activity in Drosophila cells. EMBO J. 16: 6192-6199

11. Dorstyn L, Read SH, Quinn LM, Richardson H and Kumar S (1999) DECAY, a novel Drosophila caspase related to mammalian caspase-3 and caspase-7. J. Biol. Chem. 274: 30778-30783

12. Song Z, Guan B, Bergman A, Nicholson DW, Thornberry NA, Peterson EP and Steller H (2000) Biochemical and genetic interactions between Drosophila caspases and the proapoptotic genes rpr, hid, and grim. Mol. Cell. Biol. 20: 2907-2914

13. Fraser AG and Evan GI (1997) Identification of a Drosophila melanogaster ICE/ CED-3-related protease, drICE. EMBO J. 16: 2805-2813

14. Fraser AG, McCarthy NJ and Evan GI (1997) drICE is an essential caspase required for apoptotic activity in Drosophila cells. EMBO J. 16: 6192-6199

15. Mukae N, Yokoyama H, Yokokura T, Sakoyama Y, Sakahira H and Nagata S (2000) Identification and developmental expression of inhibitor of caspaseactivated DNase (ICAD) in Drosophila melanogaster. J. Biol. Chem. 275: $21402-21408$

16. Slee EA, Harte MT, Kluck RM, Wolf BB, Casiano CA, Newmeyer DD, Wang HG, Reed JC, Nicholson DW, Alnemri ES, Green DR and Martin SJ (1999) Ordering the cytochrome c-initiated caspase cascade: hierarchical activation of caspases-2, -3, -6, -7, -8, and -10 in a caspase-9-dependent manner. J. Cell. Biol. 144: $281-292$

17. Hawkins CJ, Yoo SJ, Peterson EP, Wang SL, Vernooy SY and Hay BA (2000) The Drosophila caspase DRONC cleaves following glutamate or aspartate and is regulated by DIAP1, HID, and GRIM. J. Biol. Chem. 275: 27084-27093.

18. Kumar S and Colussi PA (1999) Prodomains, adaptors, oligomerization: the pursuit of caspase activation in apoptosis. Trends Biochem. Sci. 24: 1-4

19. Srinivasula SM, Fernandes-Alnemri T, Zangrilli J, Robertson N, Armstrong RC, Wang L, Trapani JA, KJ, Litwack G and Alnemri ES (1996) The Ced-3/interleukin 1 beta converting enzyme-like homolog Mch6 and the lamin-cleaving enzyme Mch2alpha are substrates for the apoptotic mediator CPP32. J. Biol. Chem. 271: 27099-27106

20. Duan H, Orth K, Chinnaiyan AM, Poirier GG, Froelich CJ, He WW and Dixit VM (1996) ICE -LAP6, a novel member of the ICE/Ced-3 gene family, is activated by the cytotoxic T cell protease granzyme B. J. Biol. Chem. 271: 16720-16724

21. Dorstyn L, Colussi PA, Quinn LM, Richardson Hand Kumar S (1999) DRONC, an ecdysone-inducible Drosophila caspase. Proc. Natl. Acad. Sci. USA 96: 4307 4312

22. Li P, Nijhawan D, Budihardjo I, Srinivasula SM, Ahmad M, Alnemri ES and Wang X (1997) Cytochrome $c$ and dATP-dependent formation of Apaf-1/caspase-9 complex initiates an apoptotic protease cascade. Cell. 91: 479-489

23. Rodriguez A, Oliver H, Zou H, Chen P, Wang Xand Abrams JM (1999) DARK is a Drosophila homologue of Apaf-1/CED-4 and functions in an evolutionarily conserved death pathway. Nat. Cell. Biol. 1: 272-279

24. Kanuka H, Sawamoto K, Inohara N, Matsuno K, Okano H and Miura M (1999) Control of the cell death pathway by Dapaf-1, a Drosophila Apaf-1/CED-4-related caspase activator. Mol. Cell. 4: 757-769

25. Zhou L, Song Z, Tittel J and Steller H (1999) HAC-1, a Drosophila homolog of APAF-1 and CED- 4 functions in developmental and radiation-induced apoptosis. Mol. Cell. 4: 745-755

26. Quinn LM, Dorstyn L, Mills K, Colussi PA, Chen P, Coombe M, Abrams J, Kumar $S$ and Richardson $H$ (2000) An essential role for the caspase dronc in developmentally programmed cell death in Drosophila. J. Biol. Chem. 275: 40416-40424

27. Cain K, Bratton SB, Langlais C, Walker G, Brown DG, Sun XM and Cohen GM (2000) Apaf-1 oligomerizes into biologically active approximately $700-\mathrm{kDa}$ and inactive approximately 1.4-MDa apoptosome complexes. J. Biol. Chem. 275: 6067-6070

28. Varkey J, Chen P, Jemmerson R and Abrams JM (1999) Altered cytochrome c display precedes apoptotic cell death in Drosophila. J. Cell. Biol. 144: 701-710

29. Hu S and Yang X. (2000) dFADD, a novel death domain-containing adapter protein for the Drosophila caspase DREDD. J. Biol. Chem. 275: 30761-30764

30. Muzio M, Chinnaiyan AM, Kischkel FC, O'Rourke K, Shevchenko A, Ni J, Scaffidi C, Bretz JD, Zhang M, Gentz R, Mann M, Krammer PH, Peter ME and Dixit VM (1996) FLICE, a novel FADD-homologous ICE/CED-3-like protease, is recruited to the CD95 (Fas/APO-1) death-inducing signaling complex. Cell. 85: 817-827

31. Chen P, Rodriguez A, Erskine R, Thach T and Abrams JM (1998) DREDD, a novel effector of the apoptosis activators reaper, grim, and hid in Drosophila. Dev. Biol. 201: 202-216 
32. Ashkenazi A and Dixit VM (1998) Death receptors: signaling and modulation. Science. 281: 1305-1308

33. Stöven S, Ando A, Kadalayil L, Engström Y and Hultmark D (2000) Activation of the Drosophila NF-kB factor Relish by rapid endoproteolytic cleavage. EMBO reports $1: 347-352$

34. Leulier F, Rodriguez A, Khush, RS, Abrams JM and Lemaitre B (2000) The Drosophila caspase DREDD is required to reisit Gram-negative bacterial infection. EMBO reports 1: 353-358

35. Hu WH, Johnson H and Shu HB (2000) Activation of NF-kappaB by FADD, Casper, and caspase-8. J. Biol. Chem. 275: 10838-10844
36. Miller DK, Ayala JM, Egger LA, Raju SM, Yamin TT, Ding GJ, Gaffney EP, Howard AD, Palyha OC and Rolando AM (1993) Purification and characterization of active human interleukin-1 beta-converting enzyme from THP.1 monocytic cells. J. Biol. Chem. 268: 18062-18069

37. Thress K, Henzel W, Shillinglaw W and Kornbluth S (1998) Scythe: a novel reaper-binding apoptotic regulator. EMBO J. 17: 6135-6143

38. Hay BA, Wassarman DA and Rubin GM (1995) Drosophila homologs of baculovirus inhibitor of apoptosis proteins function to block cell death. Cell. 83: $1253-1262$ 